\title{
In Vivo Analysis of Ascl1 Defined Progenitors Reveals Distinct Developmental Dynamics during Adult Neurogenesis and Gliogenesis
}

\author{
Euiseok J. Kim, ${ }^{1}$ Cheuk T. Leung, ${ }^{2}$ Randall R. Reed, ${ }^{2}$ and Jane E. Johnson ${ }^{1}$ \\ ${ }^{1}$ Department of Neuroscience, University of Texas Southwestern Medical Center, Dallas, Texas 75390, and ${ }^{2}$ Center for Sensory Biology and the Department \\ of Molecular Biology and Genetics, Johns Hopkins University School of Medicine, Baltimore, Maryland 21205
}

\begin{abstract}
In the adult mammalian brain, new neurons and glia are continuously generated but molecular factors regulating their differentiation and lineage relationships are largely unknown. We show that Ascl1, a bHLH (basic helix-loop-helix) transcription factor, transiently labels neuronal and oligodendrocyte precursors in the adult brain. Using in vivo lineage tracing with inducible Cre recombinase, we followed the maturation of these precursors in four distinct regions. In the hippocampus, Ascl1 mostly marks type-2a progenitor cells with some late stage type-1 stem cells. Thirty days after Ascll expression, although a majority of the cells matured to granule neurons, a few cells remained as immature progenitors. By 6 months, however, essentially all Ascll lineage cells were granule neurons. In contrast, in the olfactory bulb neuronal lineage, Ascll is restricted to transit amplifying cells, and by $30 \mathrm{~d}$ all cells matured into GABAergic interneurons. Ascl1 also broadly marks oligodendrocyte precursors in subcortical gray and white matter regions. In the corpus callosum, Ascl1 defines a ventral layer of early oligodendrocyte precursors that do not yet express other early markers of this lineage like PDGFR $\alpha$ and Olig2. By $30 \mathrm{~d}$, most had transitioned to mature oligodendrocytes. In contrast, Ascl1 expressing oligodendrocyte precursors in gray matter already coexpressed the early oligodendrocyte markers, but by $30 \mathrm{~d}$ they mostly remained as precursors. Our results reveal that Ascl1 is a common molecular marker of early progenitors of both neurons and oligodendrocytes in the adult brain, and these Ascl1 defined progenitors mature with distinct dynamics in different brain regions.
\end{abstract}

Key words: Mash1; bHLH transcription factor; adult neurogenesis; oligodendrocyte precursor; neural stem cell; gliogenesis

\section{Introduction}

Although most neural cell differentiation and maturation events forming the adult nervous system are completed by early postnatal periods, mitotic precursor cells for neurons, oligodendrocytes, and astrocytes continue to exist throughout the adult brain. The glial precursors such as reactive astrocytes and oligodendrocyte precursor cells (OPCs) are spread broadly throughout the adult brain (Ridet et al., 1997; Polito and Reynolds, 2005). Astrocytes are generated in response to brain injury and OPCs are slowly maturing cells that respond rapidly to demyelinating conditions (Gensert and Goldman, 1997; Ridet et al., 1997; Chari and Blakemore, 2002). In contrast, adult generated neurons arise from two restricted regions: the subgranular zone (SGZ) in the dentate gyrus of the hippocampus and the subventricular zone (SVZ) of the lateral ventricles generating olfactory bulb interneurons via

\footnotetext{
Received July 12, 2007; revised Sept. 7, 2007; accepted 0ct. 3, 2007.

We acknowledge the insightful comments of Drs. H. Lai, A. Eisch, and R. Lu, and we thank Ms J. Ables and Dr. D. Lagace in the Eisch laboratory for advice and sharing unpublished data. We are grateful for the outstanding technical assistance of Ms. J. Dumas and Mr. L. Wang for genotyping and mouse husbandry. We appreciate the generous gifts of antisera from Drs. M. Wegner for anti-Sox10, J. Kohtz for anti-Dlx, and G. Fishell for anti-BLBP. This work was supported by NIH NS032817 to JEJ and DC008295 to RRR.

Correspondence should be addressed to Jane E. Johnson, Department of Neuroscience, University of Texas Southwestern Medical Center, 5323 Harry Hines Blvd, Dallas, TX 75390-9111. E-mail: Jane.Johnson@utsouthwestern.edu. DOI:10.1523/JNEUROSCI.3178-07.2007

Copyright $\odot 2007$ Society for Neuroscience $\quad$ 0270-6474/07/2712764-11\$15.00/0
}

the rostral migratory stream (RMS) (Gage, 2000; Alvarez-Buylla and Lim, 2004). The molecular control of differentiation of these adult generated neural cell-types is much less studied than that for neural differentiation during development. However, many of the important regulatory control genes functioning during embryonic neural development are present in neuronal and glial precursors in the adult, providing models of how adult generation of neural cell-types might occur. Here, we define precursors in the adult brain expressing one such differentiation control factor, Ascl1 (previously Mash1), and we follow the progression of these cells as they differentiate to neurons and oligodendrocytes.

Ascl1 is present transiently in neural progenitor cells in complex temporal and spatial patterns throughout neural development. A mouse mutation null for Ascl1 has been studied extensively and has defined Ascl1 as a neuronal differentiation control factor in multiple regions of the developing central and peripheral nervous systems (for review, see Bertrand et al., 2002). In paradigms in which Ascll is ectopically expressed in neural progenitor cells, the cells exit the cell cycle and begin expressing neuronal differentiation markers (Farah et al., 2000; Nakada et al., 2004). However, within a particular spatial and temporal context, Ascll appears to play a role in the specification of neuronal subtype as seen in interneuron formation in the spinal cord $(\mathrm{Na}-$ kada et al., 2004; Helms et al., 2005) and cortex (Fode et al., 2000; Parras et al., 2002), and in sympathetic neurons during neural 

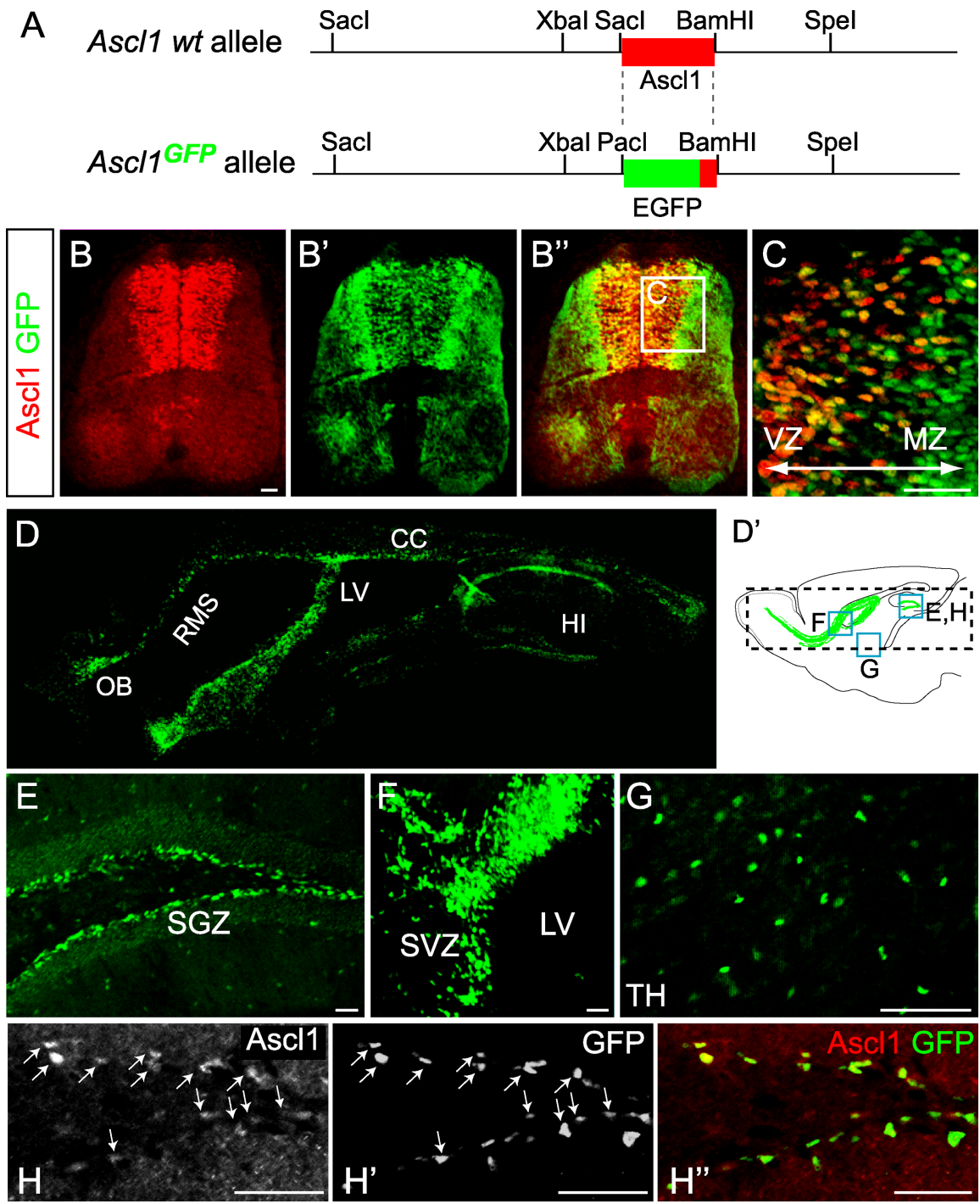

Figure 1. Ascl1-GFP expression in the adult brain. $A$, Ascl1-GFP knock-in mice have replaced one allele of $A$ scl1 coding sequence with that of a nuclear-localized GFP reporter (Leung et al., 2007). $\boldsymbol{B}-\boldsymbol{H}^{\prime \prime}$, Images from immunofluorescence of Ascl1 ${ }^{G F P /+}$ mice (Ascl1, red; GFP, green). $\boldsymbol{B}-\boldsymbol{B}^{\prime \prime}$, Transverse section of a mouse E11.5 neural tube. $\boldsymbol{C}$, Higher magnification of $\boldsymbol{B}^{\prime \prime}$ illustrating that GFP persists longer than Ascl1. Ascl1 is restricted to the ventricular zone (VZ) whereas GFP is also present in the mantle zone (MZ). D, Sagittal view of subcortical regions in mouse forebrain at P60 showing Ascl1-GFP expressing cells are enriched in adult neurogenic regions. $\boldsymbol{D}^{\prime}$, Diagram of adult mouse brain indicating where images in $\boldsymbol{D}-\boldsymbol{H}$ originated. Ascl1-GFP expression in dentate gyrus $(\boldsymbol{E})$, SVZ $(\boldsymbol{F})$ around the lateral ventricle (LV), and thalamus (TH) (G). $\boldsymbol{H}-\boldsymbol{H}^{\prime \prime}$, GFP and Ascl1 are coexpressed in SGZ of adult hippocampus (arrows). CC, Corpus callosum; HI, hippocampus; OB, olfactory bulb; RMS, rostral migratory stream. Scale bars: $40 \mu \mathrm{m}$.

crest development (Perez et al., 1999). Thus, Ascl1 is an important regulator of neuronal differentiation and subtype specification in the developing central and peripheral nervous systems.

In addition to its role in neurogenesis, Ascll also plays a role in oligodendrocyte development. Ascl1 expression has been reported in OPCs in culture (Kondo and Raff, 2000; Wang et al., 2001; Gokhan et al., 2005), and forced expression of Ascl1 in neural progenitor cultures biases fate to neurons and oligodendrocytes, but not astrocytes (Gokhan et al., 2005; Sugimori et al., 2007). Lineage tracing of Ascll expressing cells in spinal neural tube development revealed these cells are fated to neurons and oligodendrocytes, but not astrocytes in vivo (Battiste et al., 2007). At postnatal day 0 (P0) Ascll cells in the SVZ/RMS also have an oligodendrocyte producing component (Parras et al., 2004). A reduced number of oligodendrocytes were reported in the telencephalon of Ascl1 mutant embryos, suggesting Ascl1 functions in the oligodendrocyte lineage to generate the normal numbers of cells (Parras et al., 2007). Furthermore, subsets of neuroblastomas and oligodendrogliomas express Ascl1 consistent with restriction of Ascl1 to precursors of these two neural fates that may reside in the adult brain (Rousseau et al., 2006). Together these studies place Ascl1 in important regulatory roles controlling neuronal and oligodendrocyte differentiation during embryogenesis, and make Ascll a strong candidate for playing a role in these processes in the adult brain.

Here, we use a combination of genetically modified mice to definitively place Ascl1 in adult brain in progenitor cells that are transitioning to mature neurons or oligodendrocytes. Ascl1 transiently identifies a variety of neural progenitor cells early in each lineage including type-2a cells in the dentate gyrus of the hippocampus, transit amplifying cells in the SVZ and RMS in the forebrain, and immature OPCs dispersed widely in subcortical gray matter and in a ventral strip in the white matter tract of the corpus callosum. Cells that express high levels of Ascl1 transition to more mature phenotypes; they do not remain as progenitors but progress to differentiated cell types at different maturation rates in each lineage. These characteristics of Ascl1 in the adult CNS lineages are analogous to the temporal placement of Ascl1 during embryonic development revealing molecular commonality in these temporally distinct processes.

\section{Materials and Methods}

Transgenic mice and tamoxifen treatment. Ascl1CreER ${ }^{T M}, R 26 R$-stop-YFP, and Ascl1 ${ }^{G F P}$ mice were described previously. Briefly, Ascl1$C r e E R^{T M}$ is a BAC transgenic mouse where sequences encoding a Cre recombinase fused with a modified estrogen receptor replaces the Ascll coding sequence (Battiste et al., 2007). R26Rstop-YFP is a Cre recombinase reporter strain (Srinivas et al., 2001). Ascl1 ${ }^{G F P}$ has green fluorescent protein (GFP) knocked into the Ascll locus replacing the Ascll coding sequence and otherwise only modifying the locus with a short linker sequence around the ATG (Leung et al., 2007). Adult mice (P60) with the genotype Ascl1$\mathrm{CreER}^{T M} /+; \mathrm{R} 26 \mathrm{R}-$ stop-YFP/+ were injected intraperitoneally with 300 mg of tamoxifen (Sigma, St. Louis, MO) in sunflower seed oil per kilogram of body weight on 2 consecutive days. Brains were collected 5, 30, or $180 \mathrm{~d}$ after tamoxifen treatment after Avertin anesthesia and transcardiac perfusion with $4 \%$ formaldehyde. Brains were fixed further by immersion in $4 \%$ formaldehyde overnight at $4^{\circ} \mathrm{C}$, rinsed in PBS, cryoprotected in 30\% sucrose, embedded and frozen in OCT, and 40-50 $\mu \mathrm{m}$ cryosections generated. $\mathrm{P} 60 \mathrm{Ascl}^{\mathrm{GFP}}$ mice were perfused and brains processed as above.

Immunofluorescence and BrdU labeling. Free-floating sections were incubated with the appropriate dilution of primary antibody in PBS $/ 0.5 \%$ normal donkey serum $/ 0.2 \% \mathrm{NP}-40$, followed by incubation with the appropriate secondary antibodies conjugated with Alexa 488, 594, or 647 (Invitrogen). Mouse monoclonal antibodies used were as follows: GFAP 
(1:400; G3893; Sigma), bromodeoxyuridine (BrdU; 1:25; 347580; BD Biosciences, Franklin Lakes, NJ), Ascl1 (1:25; PharMingen, San Diego, CA), NeuN (1:1000; MAB377; Millipore, Temecula, CA), Ki67 (1:100; Novacastra, Newcastle, UK), glutamic acid decarboxylase (GAD67; 1:1000; Millipore), calretinin (1:500; Millipore), glutamine synthetase (1:500; Millipore), PDGFR $\alpha$ (1:200; BD Biosciences), and adenomatous polyposis coli (APC; 1:100; clone CC-1; Oncogene Sciences, Cambridge, MA). Rabbit polyclonal antibodies used were as follows: GFP (1:500; A6455; Invitrogen), GFAP (1: 500; DAKO, Carpinteria, CA), Sox2 (1:3000; Millipore), brain lipid-binding protein (BLBP; 1:20; a gift from G. Fishell, Smilow Research Center, New York, NY), Calbindin (1:1000; Swant, Bellinzona, Switzerland), tyrosine hydroxylase (TH; 1:2500; Millipore), Dlx (1:75; gift from J. Kohtz, Northwestern University, Chicago, IL), and Olig2 (1:2000; Millipore). Goat polyclonal antibodies used were as follows: anti-NeuroD (1:200; Santa Cruz Boisciences, Santa Cruz, CA), and anti-Doublecortin (1:200; Santa Cruz). Chick anti-GFP (1:500; Aves Labs, Tigard, OR) and guinea pig anti-Sox10 (1:2000; gift from $\mathrm{M}$. Wegner, Universität ErlangenNürnberg, Erlangen, Germany) were also used. For BrdU labeling, animals were injected intraperitoneally once with BrdU at $150 \mathrm{mg} / \mathrm{kg} 2 \mathrm{~h}$ before being killed. Confocal imaging was performed with a Bio-Rad (Hercules, CA) MRC 1024 or Zeiss (Oberkochen, Germany) LSM510 confocal microscope. For each experiment, multiple sections from at least three animals were analyzed except for the 6 month time point where two animals were analyzed.

\section{Results}

\section{Characterization of Ascl1 in the adult brain}

Several reports have placed Ascll in dentate gyrus of hippocampus and the SVZ of the lateral ventricles in the adult brain (Pleasure et al., 2000; Kohwi et al., 2005; Kuo et al., 2006). We confirmed these reports (Fig. $1 H$ ) and set out to obtain a more precise description of Ascl1 expression in the adult brain. Given the low sensitivity of Ascll antibodies in the adult brain, we turned to a mouse model where GFP was knocked into the Ascll locus $\left(A s c l 1^{G F P}\right)$ to perform this analysis (Leung et al., 2007) (Fig. $1 A)$. The use of GFP in the knock-in mouse to indicate Ascll expression has been validated in the olfactory epithelium (Leung et al., 2007) and here in E11.5 neural tubes (Fig. $1 B, C$ ) and adult dentate gyrus (Fig. $\left.1 \mathrm{H}-\mathrm{H}^{\prime \prime}\right)$. As reported previously, Ascl1 is spatially restricted in the ventricular zone along the rostral-caudal and dorsal-ventral axes in the developing neural tube, and disappears in more lateral regions as the cells exit the cell cycle and begin to differentiate. In Ascl $1^{G F P /+}$ embryos, GFP and Ascll are coexpressed within the ventricular zone. However, because GFP protein is more stable than Ascl1, it persists laterally into more differentiated cells (Fig. $1 B, C$ ). Thus, $A s c l 1^{G F P /+}$ can be used to identify cells that express or have recently expressed Ascll.

Analysis of P60 brains from Ascl1 ${ }^{G F P /+}$ mice revealed many GFP cells scattered throughout multiple regions (Fig. 1D). GFP was notable in the two adult neurogenic zones, the SGZ in the hippocampus and the SVZ around the lateral ventricle (Fig. $\left.1 E, F, H^{\prime}\right)$. GFP cells were also abundant in white matter including the corpus callosum, fimbria, and anterior commissure (Fig. 1D)
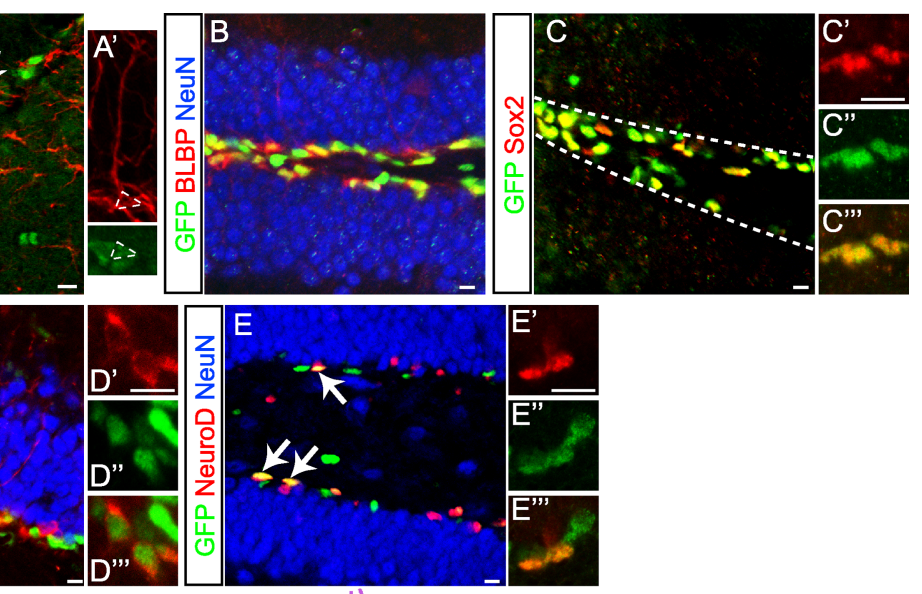

2. Ascl1-GFP cells identified as type-2 cells in the adult hippocampal neurogenic lineage. $\boldsymbol{A}-\boldsymbol{E}, \mathbf{G}$, The dentate gyrus ( shown. $F$, Characterization of the Ascl1-GFP cells places the majority at the Type-2a cell stage according to a current hippocampal neurogenesis model (Steiner et al., 2006). Dashed line indicates SGZ of the DG. Scale bars: $10 \mu \mathrm{m}$.

(data not shown). Even in gray matter such as the thalamus, scattered GFP cells were detected although expression was weaker than in other regions (Fig. 1G). Selective expression of GFP in the neurogenic zones in the hippocampus and lateral ventricles, but not in mature neuronal cell layers in the dentate gyrus or olfactory bulb suggests that Ascl1 is transiently expressed during adult neurogenesis. In addition, the extensive, dispersed GFP expression throughout the adult brain including white matter tracts is consistent with recent reports that place Ascl1 in oligodendrocyte precursors (Battiste et al., 2007; Parras et al., 2007; Sugimori et al., 2007).

Ascl1-GFP cells are largely type-2a cells along the adult hippocampal neurogenic lineage and are restricted to the granule neuron cell fate

In the adult hippocampus, putative multipotent neural stem cells reside in the SGZ and have a limited self-renewal capacity (Seri et al., 2001, 2004; Bull and Bartlett, 2005). According to a current model of the adult hippocampal neuronal lineage (for diagram, see Fig. $2 F$ ), a combinatorial set of molecules identifies each stage (Kempermann et al., 2004; Steiner et al., 2006). Briefly, type-1 neural stem cells have astrocytic features and are marked by GFAP. Although these cells have proliferative capacity, they are much more slowly cycling than the type- 2 progenitor cells. Nestin, Sox 2 and BLBP are also expressed in type- 1 cells, but they persist into the type- 2 cell stages (Steiner et al., 2006). NeuroD and Doublecortin (Dcx) appear in type-2b, the later stage of type- 2 cells, and persist into postmitotic but immature granule cell precursors. Finally, cells mature into NeuN/calbindin granule cell neurons in the dentate gyrus. 

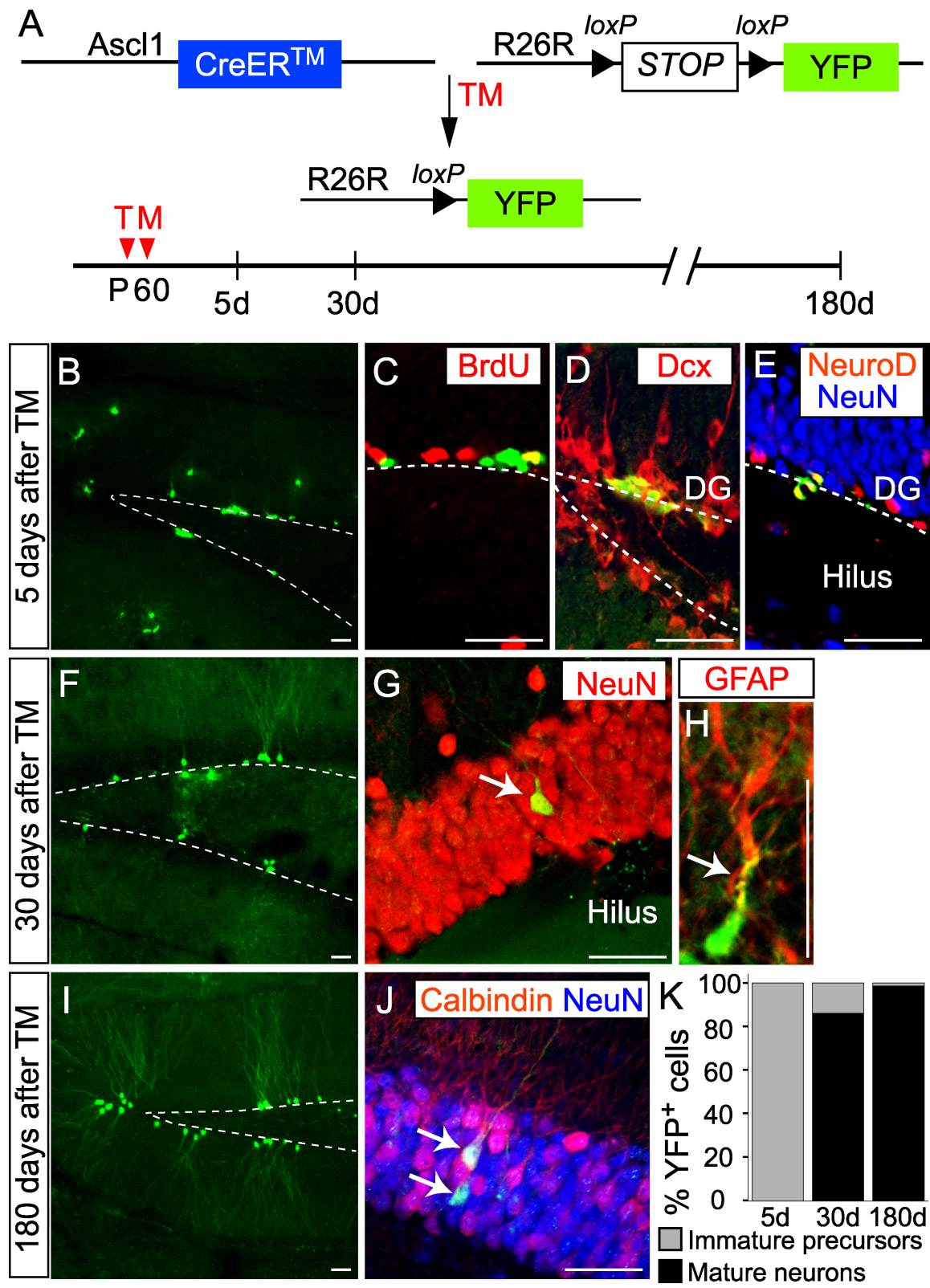

Figure 3. Ascl1 lineage cells become mature granule cells in the adult hippocampus. $\boldsymbol{A}$, Diagram illustrating the strategy for in vivo fate mapping of the Ascl1-expressing cells in adult brain. P60 mice carrying alleles Ascl1 ${ }^{\text {CreERTM }}$ (a tamoxifen inducible Cre recombinase expressed from the Ascl1 locus in a BAC transgene) and R26R-stop-YFP were treated with tamoxifen (TM) and brains were harvested 5, 30, or $180 \mathrm{~d}$ later. $\boldsymbol{B}-\boldsymbol{E}$, Five days after tamoxifen treatment YFP (green) is detected in the SGZ of the dentate gyrus (DG) (B). Only few YFP cells incorporate BrdU after a $2 \mathrm{~h}$ BrdU pulse $(\boldsymbol{C})$. In contrast, most YFP cells colabel with Dcx (D) and NeuroD $(\boldsymbol{E})$, both Type-2b/Type-3 markers. $\boldsymbol{F}-\boldsymbol{H}, 30 \mathrm{~d}$ after tamoxifen treatment YFP cells are found in the granule cell layer in the DG, have morphology of mature granule neurons, and colabel with the neuronal marker NeuN (G, arrow). A few YFP cells elicit stem cell like morphology and colabel with GFAP $(\boldsymbol{H}$, arrow). $\boldsymbol{I}, \boldsymbol{J}$, One hundred and eighty days after tamoxifen treatment YFP cells are still present in the granule cell layer, have extensive dendritic arborization, and colabel with mature granule cell markers NeuN (blue) and Calbindin (red) (J, arrows). $\boldsymbol{K}$, Quantification of the percentage of YFP cells identified as immature precursors ( $\mathrm{NeuN}^{-}$) or mature neurons $\left(\mathrm{NeuN}^{+}\right.$) at the three different time points after TM. Dashed line indicates the SGZ of the DG. Scale bars: $40 \mu \mathrm{m}$.

To identify where Ascl1 is relative to this staging scheme, we used colabeling of GFP from $A s c l 1^{G F P /+}$ brains with these different markers. The majority of GFP cells colabel with BLBP and Sox2 (Fig. $2 \mathrm{~B}, \mathrm{C}$ ). In contrast, only few GFP cells can definitively be scored as GFAP ${ }^{+}$, using the criteria that the GFP cell must be wrapped by GFAP to score it as positive for type-1 identity (Fig. $2 A$ ). Because $97 \%$ of the $\mathrm{GFP}^{+}$cells colabel with Sox 2 , they are largely classified as type-2a cells. A minority of GFP cells coexpress NeuroD (13\%) and Dcx, markers of late type-2b/3 identity

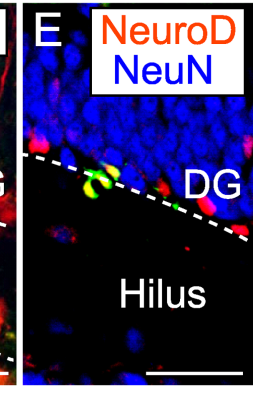

(Fig. 2D,E). Note that because GFP is more stable than endogenous Ascl1, the overlap with the type-2b markers is likely an overestimate for the endogenous protein. Furthermore, no GFP cells colabeled with the mature neuronal marker NeuN (Fig. 2B,D,E). These findings place Ascl1 temporally in type-2a cells in the dentate gyrus.

Although GFP in the $A s c l 1^{G F P}$ mouse faithfully represents endogenous Ascl1 and the short-term fate of these cells, it does not allow us to determine the ultimate fate of the Ascl1 progenitors. In fact, it takes 3-4 weeks for an adult generated neuron to reach a mature neuronal phenotype (van Praag et al., 2002). To map the fate of the Ascll lineage cells in the adult brain, we used a BAC transgenic mouse line, Ascl1-CreER ${ }^{T M}$ that expresses tamoxifen inducible Cre recombinase under the control of Ascll regulatory elements (Battiste et al., 2007) crossed with the Cre reporter line R26R-stop-YFP (Srinivas et al., 2001). In the absence of tamoxifen, brains of these animals have no detectable yellow fluorescent protein (YFP) expression. To label the Ascl1 lineage in the adult brain, Ascl1-CreER ${ }^{T M} ;$ R26R-stop-YFP mice were administered tamoxifen at $\mathrm{P} 60$ and brains were harvested after 5,30 , or $180 \mathrm{~d}$ (Fig. 3A). Recombination efficiency of the Ascl1$C r e E R^{T M}$ line in the adult hippocampus is estimated to be $6 \%$ based on comparing the number of GFP in the SGZ of $A s c l 1^{G F P /+}$ and YFP positive cells $5 \mathrm{~d}$ after tamoxifen in Ascl1-CreER ${ }^{T M} ;$ R26R-stop-YFP mice. Five days after tamoxifen administration, the YFP cells in the dentate gyrus have transitioned from type-2a to a type-3/immature neuron stage (Fig. $3 B-E$ ). This is illustrated by the decrease in the proportion of YFP labeled cells coexpressing Sox 2 and the increase in coexpression of NeuroD and Dcx relative to that seen with the Ascl1-GFP. The YFP cells form clusters in the SGZ, a characteristic of immature neuronal precursors (Seri et al., 2004), and they do not exhibit structural characteristics of mature neurons such as branched dendrites and axons (Fig. $3 B)$. Ten percent of the YFP cells incorporated $\mathrm{BrdU}$ after $2 \mathrm{~h}$ exposure $(n=210$ counted) (Fig. $3 C$ ), and $14 \%$ colabel with Sox 2 ( $n=88$ counted). The majority of YFP cells colabel with NeuroD (55\%) and Dcx (Fig. 3D,E). No overlap with the differentiated neuronal marker NeuN is seen at this time point (Fig. $3 E$ ). This combination of markers indicates that as early as $5 \mathrm{~d}$ after Ascl 1 expression, as detected by Cre recombinase activity, the lineage marked cells have largely transitioned from type2a to a type3/immature neuron stage.

By $30 \mathrm{~d}$ after tamoxifen administration, the majority of YFP cells $(86 \%)$ have continued to mature and now coexpress NeuN and exhibit dendritic processes, characteristics of granule cell neurons (Fig. $3 F, G$ ). At this time point, $14 \%$ of the YFP cells in 
the dentate gyrus retain the morphology of immature progenitors, and a subset colabel with GFAP (Fig. 3H). However, by 6 months, YFP cells in the dentate gyrus are almost exclusively $\mathrm{NeuN}^{+}$cells (98\%), and they coexpress Calbindin a marker of mature granule neurons (Fig. $3 J, K$ ). The labeled cells continue to elaborate complex dendritic processes (Fig. $3 I, J$ ). Notably, from the cellular morphology of the YFP cells within the granule zone (Cameron and McKay, 2001; van Praag et al., 2002; Liu et al., 2003), no GABAergic neurons appear to arise from Ascll cells in adult dentate gyrus. Together, these results demonstrate that the Ascll cells detected in this paradigm are mostly type 2 a progenitor cells that mature into granule cell neurons by $30 \mathrm{~d}$, with a subset marking a stem cell population of limited renewal potential.

Ascl1-GFP cells are transit amplifying cells in the SVZ and neuroblasts along the RMS and are fated to become interneurons in the olfactory bulb In adult brains of the Ascl1 $1^{\text {GFP/+ }}$ mice, many GFP cells were detected in the SVZ of the lateral ventricles and along the RMS, placing Ascl1 in this neurogenic niche as well (Fig. 1). In the SVZ and RMS, Ascl1 cells express GFP, but not all GFP cells express Ascl1 (Fig. 4A,D). The $\mathrm{GFP}^{+} /$ Ascl1 ${ }^{-}$cells likely represent differences in our ability to detect these proteins combined with the stability difference between GFP and Ascl1 previously noted. Using GFP in the Ascl ${ }^{G F P}$ knock-in to characterize the temporal and spatial characteristics of Ascl1 expression in the SVZ and RMS, we colabeled the GFP cells with a series of markers that identify cells in different stages in the development of this neurogenic region. Ki67 and Sox 2 mark proliferating neural progenitor cells. All Ki67 cells and a majority of the Sox 2 cells in the SVZ and RMS colabel with GFP, but with no clear colabeling of the stem cell marker GFAP (Fig. $4 B, C$ ). This combination of markers is consistent with Ascl1-GFP cells being the rapidly dividing transit amplifying cells rather then the slowly dividing neural stem cells. In addition, a majority of GFP cells located further along the RMS coexpress Dlx and Dcx, identifying them as neuroblasts (Fig. 4G,H). A few GFP cells colabel with Olig2 (Fig. $4 F$ ) consistent with previous reports for Olig2 expression in the RMS (Hack et al., 2005). Notably, the GFP cells extend from the SVZ and into the RMS, but are not found in the olfactory bulb and do not colabel with NeuN (Fig. $4 E$ ). Thus, in the adult brain, Ascl1-GFP cells comprise transit amplifying cell populations and neuroblasts in this neurogenic lineage (Fig. 4I).

We used the Ascl1-CreER ${ }^{T M}$;R26R-stop-YFP mouse to determine the fate of the Ascll cells and to further examine whether SVZ stem cells express Ascl1. Just $5 \mathrm{~d}$ after tamoxifen administration in a P60 mouse, although some YFP cells were found around

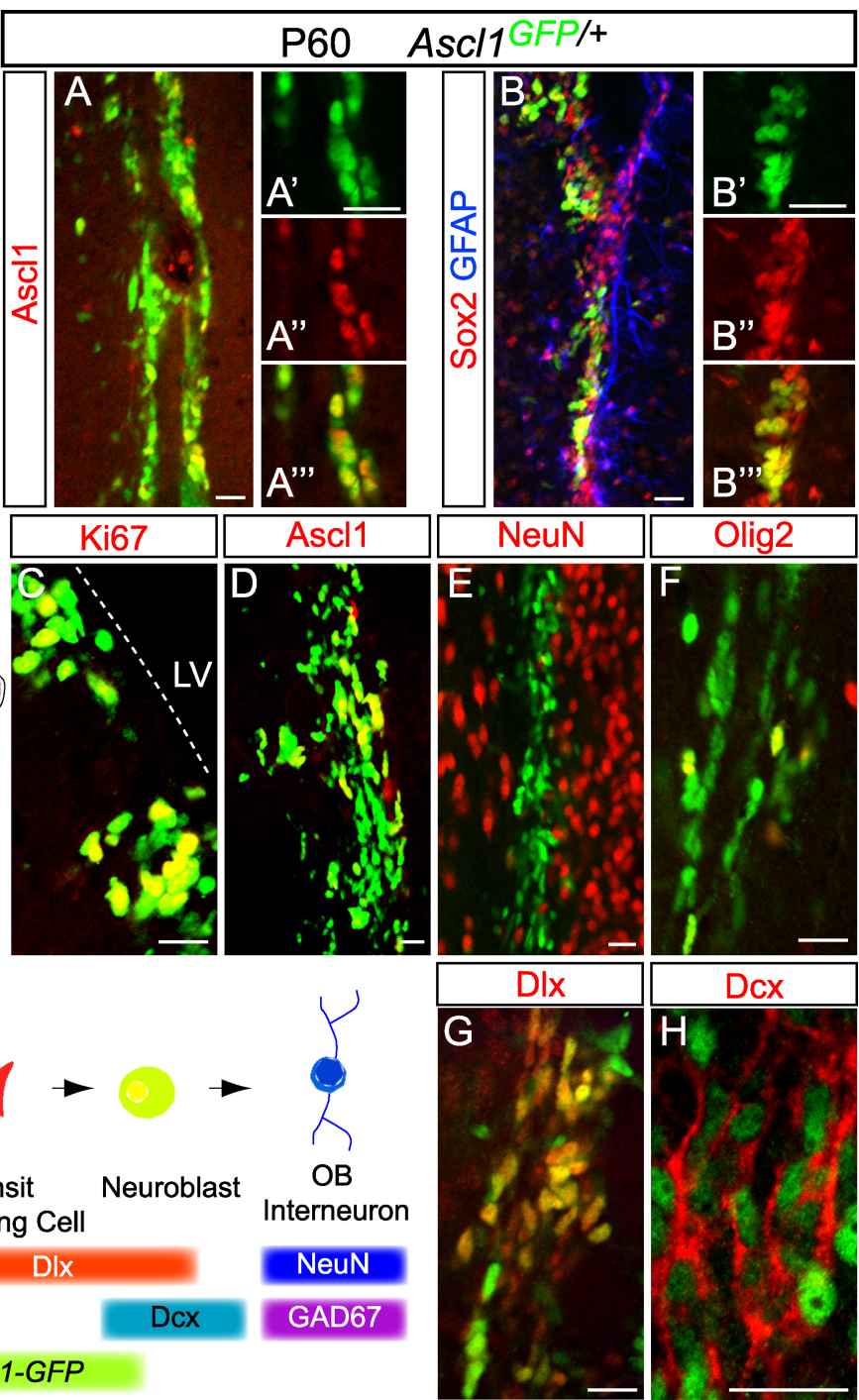

Figure 4. Ascl1-GFP cells are transit amplifying cells or neuroblasts in the SVZ and rostral migratory stream. $\mathbf{A}-\mathbf{H}$, Immuno(a) 2, Olig2, Dlx, and Dcx, but not GFAP or NeuN identifying Ascl1-GFP cells as transit amplifying/neuroblast cells in this neurogenic ulb neurogenesis (Doetsch, 2003). Diagrams depict the SVZ in a coronal view, or the SVZ and RMS in a sagittal view of an adult brain showing the location of the GFP cells and regions imaged in $\boldsymbol{A}-\boldsymbol{H}$. LV, Lateral ventricle. Scale bar: $20 \mu \mathrm{m}$.

the SVZ (Fig. 5A), the majority of Ascl1 lineage YFP cells were found along the RMS (Fig. $5 B, C$ ). As predicted from their location, the YFP cells in the SVZ coexpressed Sox2 (87\%) (Fig. 5A, inset) and Dcx (93\%). In contrast, essentially all the YFP cells in RMS were Dcx neuroblasts (Fig. 5D). At this time point, YFP cells did not colabel with NeuN and cells had not reached the olfactory bulb (data not shown). In contrast, after $30 \mathrm{~d}$, all YFP cells were found in the olfactory bulb (Fig. 5 $A^{\prime}-C^{\prime}$ ). Strikingly, no YFP cells were found in the SVZ or the RMS (Fig. $5 A^{\prime}, B^{\prime}$ ). These results clearly demonstrate that cells expressing Ascll at levels detected in this paradigm are not stem cells but rather are transit amplifying cells that within $30 \mathrm{~d}$ have completed their migration to the olfactory bulb and differentiated into neurons.

Unlike adult generated granule neurons in hippocampus, which appear to be a uniform neuronal subtype, newly generated olfactory bulb neurons are heterogeneous in two distinctive layers, the granule cell layer (GCL) and the glomerular layer (GL) 

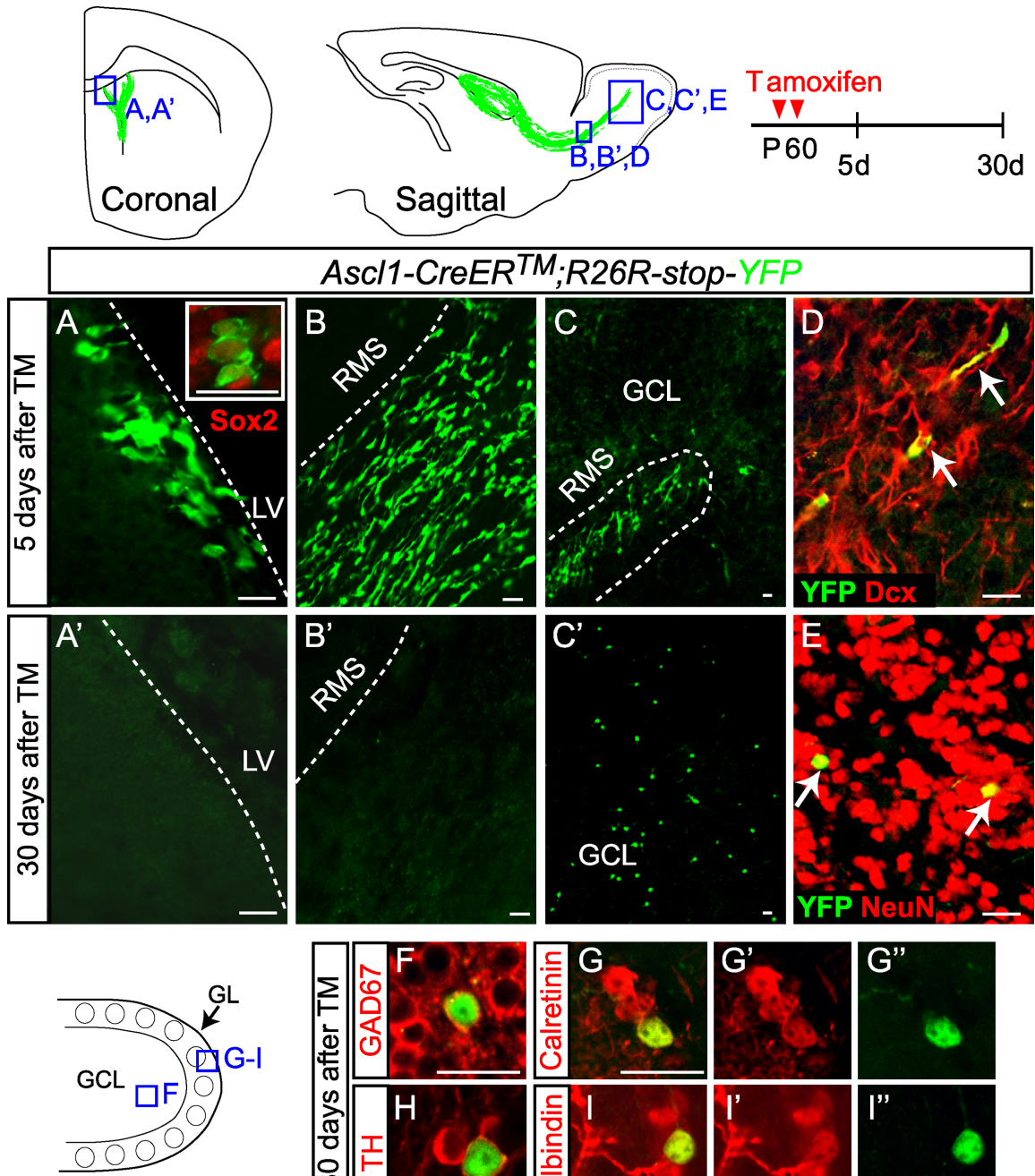

Olf Bulb
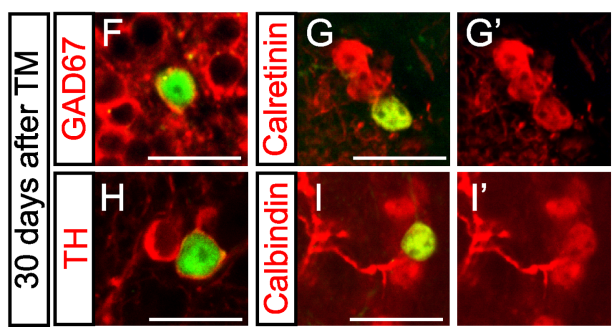

Figure 5. Ascl1 lineage cells become interneurons in granule and periglomerular layers of the olfactory bulb. Immunofluores-

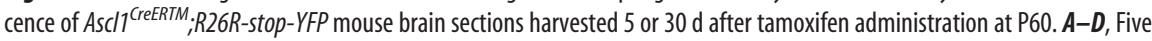
days after tamoxifen treatment some YFP cells (green) are located near the SVZ ( $\boldsymbol{A})$ and colabel with Sox2 $(\boldsymbol{A}$, inset; red), but most YFP cells were found within the RMS $(\boldsymbol{B}, \boldsymbol{C})$ and colabel with the neuroblast marker Dcx ( $\boldsymbol{D}$, arrows). In contrast, $30 \mathrm{~d}$ after tamoxifen treatment no YFP cells were detected around the SVZ or RMS $\left(\boldsymbol{A}^{\prime}, \boldsymbol{B}^{\prime}\right)$. At this time the YFP cells were found in the olfactory bulb ( $\left.\boldsymbol{C}^{\prime}\right)$ and express the mature neuronal marker $\operatorname{NeuN}(\boldsymbol{E}$, arrows). $\boldsymbol{F}-\boldsymbol{I}$, Most YFP cells in the olfactory bulb $30 \mathrm{~d}$ after tamoxifen treatment localized to the GCL where newly generated neurons are homogenously GABAergic shown here as overlap with GAD67 $(\boldsymbol{F})$. A much smaller proportion of YFP cells were located near the GL in diverse interneuron types overlapping with calretinin $(\boldsymbol{G})$, TH $(\boldsymbol{H})$, or calbindin $(\boldsymbol{I})$. Diagrams depict SVZ in a coronal section, or SVZ and RMS, or olfactory bulb in a sagittal section of an adult mouse brain. Boxes indicate the location where images were taken. LV, Lateral ventricle; TH, tyrosine hydroxylase; TM, tamoxifen. Scale bars: $20 \mu \mathrm{m}$.

(Altman, 1969; Luskin, 1993; Lois and Alvarez-Buylla, 1994). The GCL and the GL comprises GABAergic neurons, however, in the GCL this appears as a homogeneous population whereas in the GL the cells can be classified as dopaminergic, calbindin ${ }^{+}$, or calretinin $^{+}$(Kosaka et al., 1995, 1998; Saghatelyan et al., 2004; Kohwi et al., 2007). To determine whether the Ascll lineage contributes to all neuronal subtypes in the olfactory bulb the YFP cells $30 \mathrm{~d}$ after tamoxifen treatment were examined with the different markers. Based on the location in the olfactory bulb, $88 \%$ of YFP cells were located in the GCL and 12\% were found in the GL (780 cells counted). The identity of the YFP cells in the GCL as GABAergic neurons was confirmed by colabeling with NeuN and the GABAergic marker GAD67 (Fig. 5 E, F). The YFP cells located in the GL were colabeled with calbindin, calretinin, or the dopaminergic marker TH (Fig. 5G-I), indicating the Ascl1 lineage in

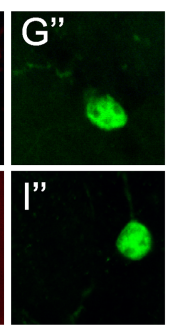

the GL neurons was not biased toward one specific neuronal subtype. Thus, other than GABAergic identity, Ascl1 does not appear to specify neuronal subtype in the olfactory bulb.

Ascl1 is an early marker for adult oligodendrocyte progenitor cells Oligodendrocytes are generated during embryogenesis and throughout adult life. Adult OPCs are identified by PDGFR $\alpha$ or NG2 and constitute the major dividing cell population contributing to myelination repair in response to brain injury (Chari and Blakemore, 2002; Reynolds et al., 2002; Dawson et al., 2003; Woodruff et al., 2004; Polito and Reynolds, 2005). Ascl1 is present in oligodendrocyte progenitors during embryogenesis, in early postnatal brain, and in the adult brain (Parras et al., 2004, 2007; Battiste et al., 2007). We investigated Ascll in this lineage using our mouse models. GFP cells in P60 Ascl1 ${ }^{\text {GFP/+ }}$ brains showed intense signals in a discrete line along white tracts throughout the corpus callosum (Fig. 6A), whereas weaker signals from scattered cells were detected in gray matter such as the thalamus (Fig. $6 H)$. In the corpus callosum, the GFP cells mainly formed clusters in a narrow line that colabel with Ascl1, validating the use of GFP in the knock-in to characterize these cells (Fig. 6B). These GFP cells colabeled with BrdU incorporation and Sox2 identifying them as proliferating neural progenitor cells (Fig. 6C,D). Restriction of the GFP cells in a specific region within the corpus callosum suggests it identifies an adult oligodendrogenic region (Seri et al., 2006). Furthermore, the GFP cells are partially overlapping with the OPC markers PDGFR $\alpha$, Olig2 or Sox10, but not with the mature oligodendrocyte marker APC, indicating that Ascl1 is present in progenitors before the known early oligodendrocyte markers are detected (Fig. 6E-G) (data not shown). In contrast, in gray matter regions such as the thalamus, most Ascl1-GFP cells express the OPC markers PDGFR $\alpha$, Olig2, and Sox10, but not the mature oligodendrocyte marker APC (Fig. $6 I-L)$. This contrast suggests Ascl1-GFP cells are marking OPCs at different developmental stages in the adult brain depending on the environmental context.

To follow the Ascll lineage cells over time in the OPCs, we analyzed YFP cells outside the neurogenic zones in the Ascl1CreER ${ }^{T M}$;R26R-stop-YFP animals induced with tamoxifen at P60. Five days after tamoxifen administration, YFP cells were detected in the white matter including corpus callosum, fimbria and internal capsule, and in gray matter regions including the hippocampal formation and thalamus (Fig. 7A-C) (data not shown). Comparison between GFP and YFP cells in the corpus callosum of $A s c l 1^{G F P /+}$ and Ascl1-CreER ${ }^{T M} ; \mathrm{R} 26 \mathrm{R}$-stop-YFP mice, respectively, gives an estimated recombination efficiency for Cre 
of $13 \%$. Regardless of their location in the brain, almost all YFP cells coexpressed PDGFR $\alpha$, Olig2, and Sox10 (96\%) indicating they are in the oligodendrocyte lineage (Fig. 7D-F) (shown here in thalamus but also seen in corpus callosum). Thus, the subpopulations of GFP cells identified in the corpus callosum of $A s c l 1^{G F P /+}$ that were negative for Olig2 and Sox10, began expressing these oligodendrocyte lineage markers within $5 \mathrm{~d}$ of Ascll expression. Notably, Ascl1 is transient in this lineage because at $5 \mathrm{~d}$ after tamoxifen treatment, there was little overlap in YFP and Ascl1 (Fig. $7 A)(1 \% n=91$ cells counted). Many YFP cells were observed as doublets, suggesting they had recently divided (Fig. 7C). The Ascl1 lineage marked cells had not progressed to a mature oligodendrocyte because only a small fraction of YFP cells (4\%) colabeled with APC (Fig. 7G). Together these results illustrate that Ascl1 is transiently expressed in early OPCs that are actively differentiating.

To determine whether the Ascll lineage cells progress to mature oligodendrocyte, we examined the YFP cells $30 \mathrm{~d}$ after tamoxifen administration. Comparison of the YFP cells in the corpus callosum and thalamus revealed that the OPCs in each region mature at different rates. In the corpus callosum, 58\% of the Ascl1 lineage cells matured into differentiated oligodendrocytes and colabeled with Sox 10 and APC (Fig. $7 H-J, N$ ), whereas in the thalamus only $20 \%$ of the cells colabeled with APC (Fig. $7 K-N)$. Previous studies have suggested that OPCs in the adult $\mathrm{CNS}$ are arrested at a precursor stage as assessed by retroviral infection or BrdU birthdating (Gensert and Goldman, 1997; Dawson et al., 2003). This does not appear to be true for the Ascl1 expressing OPCs in the white matter tract because a majority of the OPCs matured into oligodendrocytes. Even in thalamus the OPCs are maturing but not as efficiently as in the corpus callosum.

Previous studies in the developing spinal cord and neonatal brain placed Ascl1 in neuronal and oligodendrocytic lineages but not astrocytic lineages (Parras et al., 2004; Battiste et al., 2007). Consistent with these embryonic studies, the adult Ascl1 lineage cells do not contribute to the astrocyte lineage because overlap with YFP and the astrocyte marker GFAP or glutamine synthetase was not detected (supplemental Fig. 1, available at www.jneurosci. org as supplemental material). Thus, even in the adult neural progenitor cells, Ascl1 lineage is restricted to progenitors to neurons and oligodendrocytes, but not astrocytes.

\section{Discussion}

Ascll is unique in that it is a transcription factor with essential regulatory functions in directing both neurogenesis and oligodendrogenesis. In both lineages, Ascll is transient and identifies early neural precursor cells. These characteristics of expression are seen in the adult brain as well as in the developing neural tube, highlighting molecular similarities between these temporally distinct processes. In the adult brain, we have defined the profile of Ascll expressing neural precursor cells and subsequently followed the lineage of these cells in four distinct brain regions (Fig.
8). These regions will be discussed in turn and include the two regions giving rise to new neurons, the SGZ of the dentate gyrus and the SVZ/RMS supplying neurons to the olfactory bulb, and two regions with distinct OPCs, the corpus callosum as a white matter tract and the thalamus representing a subcortical gray matter region.

One consideration to keep in mind in interpreting results from in vivo lineage analysis using the Ascl1-CreER ${ }^{T M}$ mice is that we might only detect recombination in a subset of the Ascll expressing cells, likely those with the highest expression of Ascl1. Indeed, within $2 \mathrm{~d}$ after tamoxifen treatment, the vast majority of $\mathrm{YFP}^{+}$cells coexpress Dcx in the SVZ. This suggests that as soon as we can detect the reporter YFP, the cells are at a slightly later stage than cells containing endogenous Ascl1. This result is consistent with our observations using this same mouse strain for embryonic neural tube studies (Battiste et al., 2007). These results do not, however, eliminate the possibility that we get recombination in early progenitors. We know that ectopically expressing Ascl1 in chick neural tube causes cells to rapidly differentiate (Nakada et al., 2004). Thus, it is possible that the early progenitors with Ascl1-Cre expression have progressed rapidly into $\mathrm{Dcx}^{+}$progenitors in the SVZ. We cannot at this time discriminate whether we are detecting the lineage of late progenitors expressing high Ascll, or whether cells that express Ascll progress rapidly to the next stage of differentiation.

\section{Ascl1 lineage in adult neurogenesis in the dentate gyrus of} the hippocampus

Using the $A s c l 1^{G F P /+}$ mouse, our study identifies the majority of Ascl 1 cells as type-2a cells with a minority being type- 1 cells in the adult dentate gyrus. According to a current model of adult hippocampus neurogenesis, GFAP, Sox2, and Nestin expressing neural stem cells (type-1 cells) differentiate into neural progeni- 

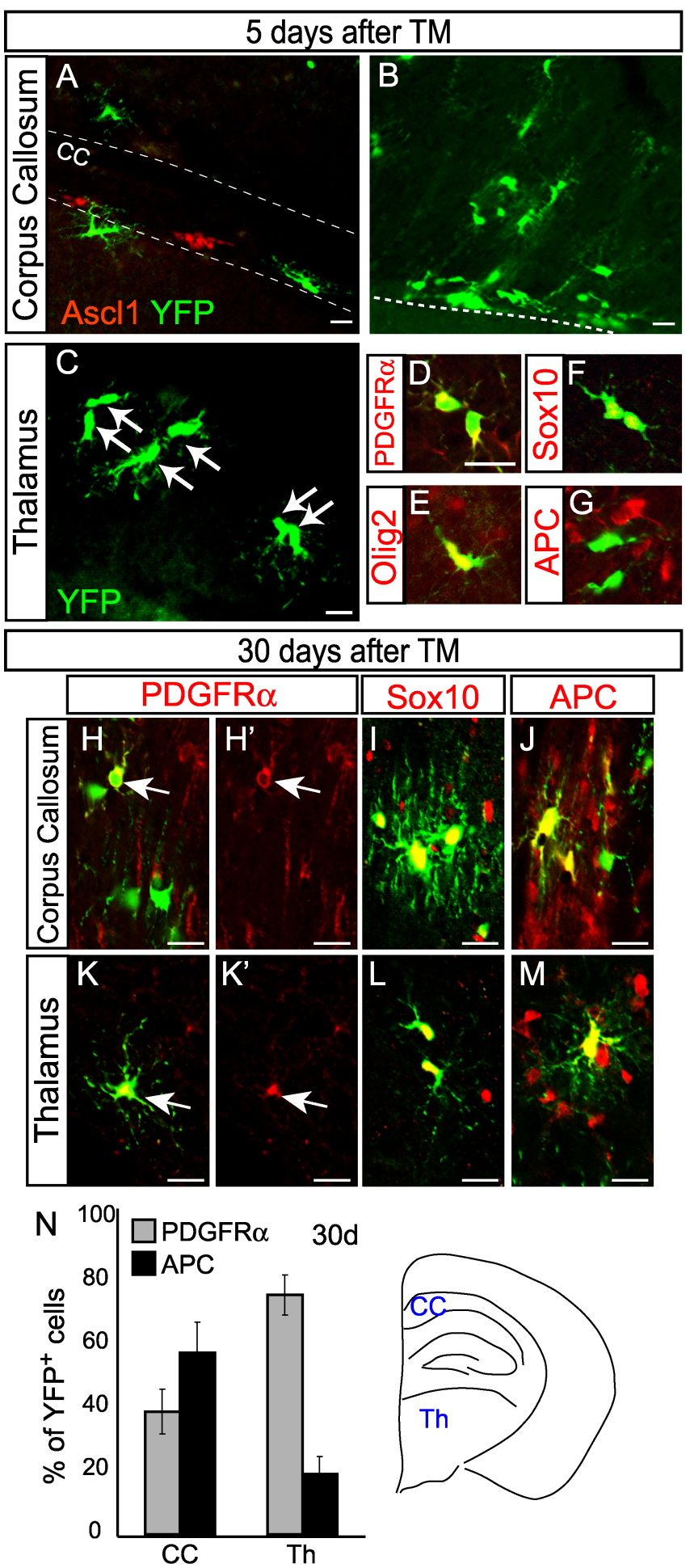

Figure 7. Ascl1-lineage OPCs become mature oligodendrocytes in the adult brain. Immunofluorescence of Ascl1 ${ }^{\text {CreERTM }}, R 26 R$-stop-YFP mouse brain sections harvested 5 or $30 \mathrm{~d}$ after tamoxifen administration at P60. $\boldsymbol{A}-\mathbf{G}$, Five days after tamoxifen administration, YFP cells (green) in corpus callosum no longer colabel with Ascl1 and they appear to spread from the ventral surface $(\boldsymbol{A}, \boldsymbol{B})$.YFP cells are often found as doublets, indicating they were recently dividing, and illustrated here in thalamus (C, arrows). In both the corpus callosum and thalamus, YFP cells colabel with the OPC markers Olig2 (D), PDGFR $\alpha(\boldsymbol{E})$, and Sox10 $(\boldsymbol{F})$, but not the mature oligodendrocyte marker $\operatorname{APC}(\boldsymbol{G})$. $\boldsymbol{H}-\mathbf{N}$, Thirty days after tamoxifen administration, in both corpus callosum $(\boldsymbol{H}-\boldsymbol{J})$ and thalamus $(\boldsymbol{K}-\boldsymbol{M})$, YFP cells colabel with OPC markers PDGFR $\alpha\left(\boldsymbol{H}, \boldsymbol{H}^{\prime}, \boldsymbol{K}, \boldsymbol{K}\right)$ and Sox10 $(\boldsymbol{I}, \boldsymbol{L})$, but also with the mature oligodendrocyte marker APC $(\boldsymbol{J}, \boldsymbol{M}) . \boldsymbol{N}$, Quantification of the percentage of YFP cells colabeled with the OPC marker PDGFR $\alpha$ or the mature oligodendrocyte marker APC in both corpus callosum (CC) and thalamus (Th) $30 \mathrm{~d}$ after tamoxifen. Diagram depicts the $\mathrm{CC}$ and Th in adult coronal brain where images were taken. Scale bars: $20 \mu \mathrm{m}$. tor cells expressing NeuroD and Dcx (type-2b or 3 cells). Previous reports place transcription factors, Tbr2 and Neurog2, in the type-2b or 3 cells as well, a stage after Ascll expression (Hevner et al., 2006; Ozen et al., 2007). Ascl1 is a unique marker for type-2a cells, and in particular it marks cells that are actively transitioning from progenitor to differentiated neuron. Long-term fate mapping of Ascll progenitors also supports this idea, showing that by 6 months almost all of the progeny in the hippocampus have matured into granule neurons. In contrast, using similar paradigms but with the inducible Cre under the control of Gli1 (Ahn and Joyner, 2005) or Nestin (Lagace et al., 2007), stem cell populations are not depleted and generate neurons continuously. Although Ascll appears to largely mark type-2a cells, there is some overlap detected in $\mathrm{GFAP}^{+}$cells. Indeed, $30 \mathrm{~d}$ after tamoxifen induction in the Ascl1-CreER- mice, there are still cells that have stem cell/progenitor cell morphology and do not label with NeuN. However, as stated above this population is almost completely depleted by 6 months. Therefore, we suggest GFAP (type-1) cells that reach a level of Ascl1 expression detected here, have less potential for self-renewal than a type-1 cell coexpressing GFAP and Nestin or Gli1. Our results are consistent with the premise that $\mathrm{GFAP}^{+}$SGZ cells can be divided into cells having long-term self-renewal $\left(\mathrm{GFAP}^{+} / \mathrm{Ascl}^{-}\right)$and cells with more limited dividing potential $\left(\mathrm{GFAP}^{+} / \mathrm{Ascl}^{+}\right.$) (Seki et al., 2007).

Ascl1 lineage in adult neurogenesis in the SVZ/RMS and the generation of olfactory bulb interneurons

Ascll transiently marks transit amplifying cells and neuroblasts in adult olfactory bulb neurogenesis (Kohwi et al., 2005). In this lineage, neural stem cells residing around the lateral ventricle wall migrate along the RMS to the olfactory bulb as they differentiate. GFP cells in the Ascl1 ${ }^{\text {GFP/+ }}$ mouse show broad but discrete expression of GFP along this pathway. These cells are Sox ${ }^{+}, \mathrm{Ki}_{67}{ }^{+}$ or $\mathrm{Dcx}^{+}$, indicating their identity as amplifying neural progenitor cells, consistent with previous reports using a transgenic mouse with Ascl1 regulatory sequences driving LacZ (Parras et al., 2004). The Ascl1-CreER ${ }^{T M}$ mouse allowed us to determine the timing of differentiation and to examine whether Ascll cells continue to self-renew. Strikingly, $30 \mathrm{~d}$ after Ascl1 expression, the Ascll lineage cells were located in the olfactory bulb, with none found in the SVZ or RMS demonstrating all Ascl1 lineage cells detected in this paradigm differentiate and none stay as stem/ progenitor cells. In contrast, in similar paradigms but using Nestin (Kuo et al., 2006) or Gli1 (Ahn and Joyner, 2005) to drive the inducible Cre, the stem cell and progenitor populations maintain the lineage marker over time in SVZ and RMS. Clear differences between Ascl1-CreER ${ }^{T M}$ and Nestin- and Gli1CreER ${ }^{T 2}$ suggest that comparisons between these model systems will elucidate novel information (i.e., via gene expression profiling) regarding stem and transit amplifying cells at distinct stages during adult neurogenesis.

\section{Ascl1 lineage neurons in adult hippocampus and olfactory} bulb have diverse neuronal subtypes

During embryogenesis, Ascll functions in neuronal differentiation and subtype specification for diverse cell types throughout the nervous system. In the dorsal spinal cord, Ascll functions in specifying glutamatergic interneuron populations $\mathrm{dI} 3$ and $\mathrm{dI} 5$ (dorsal interneuron 3 and 5) (Helms et al., 2005). In telencephalon development, Ascl1 functions with Dlx2 to generate the GABAergic neurons that migrate to the cortex (Fode et al., 2000; Parras et al., 2002; Long et al., 2007). And in the peripheral nervous system, Ascl1 biases neural crest cells to the autonomic lin- 
eage rather than the sensory (Perez et al., 1999). Thus, although Ascll appears to play a role in neuronal subtype specification, the specific neuronal subtypes formed depend on the cellular environment and developmental history. This concept for Ascll function in neuronal specification holds in the adult as well. Ascll lineage neurons in the adult hippocampus generate exclusively glutamatergic neurons, with no evidence for Ascl1 progenitors giving rise to GABAergic neurons in this region. In contrast, adult generated Ascll lineage cells in the olfactory bulb are all GABAergic neurons with no obvious preference toward individual subtypes distinguished by $\mathrm{TH}$, calretinin, and calbindin in the glomerular layer.

\section{Ascl1 lineage in adult oligodendrogenesis in the corpus callosum}

Analyzing the Ascl1 ${ }^{G F P /+}$ mouse brain for GFP and endogenous Ascl1, we find many Ascll expressing cells in the adult corpus callosum, a wide axon bundle containing myelinated oligodendrocytes beneath the neocortex. The Ascl1 population forms a discrete layer of cells along the ventral side of the corpus callosum, a region reported to be enriched in progenitor cells in the adult brain (Seri et al., 2006). Other oligodendrocyte markers including those considered early markers such as PDGFR $\alpha$ and Olig2 do not show this distinct pattern, but rather are distributed throughout the corpus callosum. This observation suggests that Ascl1 is the earliest OPC marker identified and that the discrete line of Ascll cells in the corpus callosum defines an oligodendrogenic niche. Supporting this idea, Ascl1-GFP cells mostly express Sox2, but only partially overlap with early OPC markers such as Olig2 and Sox10, suggesting Ascl1 expression is before these markers. Consistent with this, using the inducible Cre system to follow the lineage, the Ascll cells have progressed to PDGFR $\alpha^{+}$and Sox $10^{+}$OPCs within $5 \mathrm{~d}$, with many of these cells appearing as doublets. In addition, in late stage spinal cord embryogenesis, Ascll expresses earlier than Sox10 and Olig2 as well (E. J. Kim, unpublished observation). At E15.5, early precursor cells are lined along ventricular zone and move out as they mature to oligodendrocytes. Within the ventricular zone, there are few Ascll cells colabeled with Olig2/Sox10, whereas in the mantle zone they are more likely to coexpress Olig2/Sox10. Therefore, in oligodendrogenic niches, Ascl1 marks OPCs at an earlier stage than Olig2 and Sox10. Furthermore, in the adult, Ascll expression is transient and disappears as the other OPC markers remain.

The transient nature of Ascl1 in the OPC lineage makes the Ascl1-CreER ${ }^{T M}$ mouse uniquely suited to follow the progression of OPCs as they mature in the adult brain. Oligodendrocyte progenitors marked by Ascl1-CreER ${ }^{T M}$ differentiate within $30 \mathrm{~d}$ to express APC, a mature oligodendrocyte marker. This indicates Ascl1 ${ }^{+}$OPCs in the corpus callosum are not quiescent, but actively mature even in an intact noninjured brain. Previous studies using stereotactic injection of retrovirus or BrdU birthdating showed cycling cells in the corpus callosum only rarely mature into myelinating oligodendro- cytes, with the rate of maturation dramatically increased after brain insult (Gensert and Goldman, 1997; Dawson et al., 2003). It is possible that the Ascl1 lineage marked cells in the corpus callosum identify a subset of the cells marked in the previous studies, a subset that is more actively maturing.

\section{Ascl1 lineage in adult oligodendrogenesis in subcortical gray matter: thalamus}

Not only white matter but also subcortical gray matter contains widespread Ascl1-GFP cell populations. The Ascl1 marked OPCs in the thalamus already coexpress Sox10, Olig2, and PDGFR $\alpha$, indicating they are committed oligodendrocyte progenitors as previous studies reported (Woodruff et al., 2001). These cells also contrast in their rate of maturation with the Ascl1 OPCs in the corpus callosum in that they mature more slowly and after $30 \mathrm{~d}$ the majority remains immature, expressing PDGFR $\alpha$ and not APC. Different antigenic profiles and differentiation rates of Ascll lineage OPCs between the white matter tract of the corpus callosum and gray matter of the thalamus suggest Ascl1 is marking different subsets of OPCs. Future studies will be needed to determine whether this also represents a functional distinction.

\section{Concluding remarks}

Here we show the first comprehensive lineage analysis from Ascl1-expressing cells in adult brain. Adult Ascl1 expressing cells share similar molecular characteristics with embryonic counterparts and differentiate into mature neural cells. Along with the previous studies regarding the expression of other transcription factors and signaling molecules such as Notch, Shh, and Wnt in adult brain (Stump et al., 2002; Ahn and Joyner, 2005; Hack et al., 2005; Lie et al., 2005; Ozen et al., 2007), this study supports the idea that adult CNS controls 
neural stem cell differentiation using similar molecular mechanisms as in the embryonic CNS. Ascl1 is unique as a classII bHLH transcription factor in that it is involved in both adult neurogenesis and oligodendrogenesis, and its expression is restricted within narrow developmental windows in both processes. This characteristic of Ascl1 expression makes the Ascl1CreER ${ }^{T M}$ mouse a valuable tool for studying the developmental dynamics of adult born neurons and oligodendrocytes that will contribute insights into underlying causes of brain tumor development and other neurological disorders.

\section{References}

Ahn S, Joyner AL (2005) In vivo analysis of quiescent adult neural stem cells responding to Sonic hedgehog. Nature 437:894-897.

Altman J (1969) Autoradiographic and histological studies of postnatal neurogenesis. IV. Cell proliferation and migration in the anterior forebrain, with special reference to persisting neurogenesis in the olfactory bulb. J Comp Neurol 137:433-457.

Alvarez-Buylla A, Lim DA (2004) For the long run: maintaining germinal niches in the adult brain. Neuron 41:683-686.

Battiste J, Helms AW, Kim EJ, Savage TK, Lagace DC, Mandyam CD, Eisch AJ, Miyoshi G, Johnson JE (2007) Ascll defines sequentially generated lineage-restricted neuronal and oligodendrocyte precursor cells in the spinal cord. Development 134:285-293.

Bertrand N, Castro DS, Guillemot F (2002) Proneural genes and the specification of neural cell types. Nat Rev Neuroscience 3:517-530.

Bull ND, Bartlett PF (2005) The adult mouse hippocampal progenitor is neurogenic but not a stem cell. J Neurosci 25:10815-10821.

Cameron HA, McKay RD (2001) Adult neurogenesis produces a large pool of new granule cells in the dentate gyrus. J Comp Neurol 435:406-417.

Chari DM, Blakemore WF (2002) Efficient recolonisation of progenitordepleted areas of the CNS by adult oligodendrocyte progenitor cells. Glia 37:307-313.

Dawson MR, Polito A, Levine JM, Reynolds R (2003) NG2-expressing glial progenitor cells: an abundant and widespread population of cycling cells in the adult rat CNS. Mol Cell Neurosci 24:476-488.

Doetsch F (2003) The glial identity of neural stem cells. Nat Neurosci 6:1127-1134.

Farah MH, Olson JM, Sucic HB, Hume RI, Tapscott SJ, Turner DL (2000) Generation of neurons by transient expression of neural bHLH proteins in mammalian cells. Development 127:693-702.

Fode C, Ma Q, Casarosa S, Ang SL, Anderson DJ, Guillemot F (2000) A role for neural determination genes in specifying the dorsoventral identity of telencephalic neurons. Genes Dev 14:67-80.

Gage FH (2000) Mammalian neural stem cells. Science 287:1433-1438.

Gensert JM, Goldman JE (1997) Endogenous progenitors remyelinate demyelinated axons in the adult CNS. Neuron 19:197-203.

Gokhan S, Marin-Husstege M, Yung SY, Fontanez D, Casaccia-Bonnefil P, Mehler MF (2005) Combinatorial profiles of oligodendrocyte-selective classes of transcriptional regulators differentially modulate myelin basic protein gene expression. J Neurosci 25:8311-8321.

Hack MA, Saghatelyan A, de Chevigny A, Pfeifer A, Ashery-Padan R, Lledo PM, Gotz M (2005) Neuronal fate determinants of adult olfactory bulb neurogenesis. Nat Neurosci 8:865-872.

Helms AW, Battiste J, Henke RM, Nakada Y, Simplicio N, Guillemot F, Johnson JE (2005) Sequential roles for Mash1 and Ngn2 in the generation of dorsal spinal cord interneurons. Development 132:2709-2719.

Hevner RF, Hodge RD, Daza RA, Englund C (2006) Transcription factors in glutamatergic neurogenesis: conserved programs in neocortex, cerebellum, and adult hippocampus. Neurosci Res 55:223-233.

Kempermann G, Jessberger S, Steiner B, Kronenberg G (2004) Milestones of neuronal development in the adult hippocampus. Trends Neurosci 27:447-452.

Kohwi M, Osumi N, Rubenstein JL, Alvarez-Buylla A (2005) Pax6 is required for making specific subpopulations of granule and periglomerular neurons in the olfactory bulb. J Neurosci 25:6997-7003.

Kohwi M, Petryniak MA, Long JE, Ekker M, Obata K, Yanagawa Y, Rubenstein JL, Alvarez-Buylla A (2007) A subpopulation of olfactory bulb GABAergic interneurons is derived from Emx1- and Dlx5/6-expressing progenitors. J Neurosci 27:6878-6891.
Kondo T, Raff M (2000) Basic helix-loop-helix proteins and the timing of oligodendrocyte differentiation. Development 127:2989-2998.

Kosaka K, Aika Y, Toida K, Heizmann CW, Hunziker W, Jacobowitz DM, Nagatsu I, Streit P, Visser TJ, Kosaka T (1995) Chemically defined neuron groups and their subpopulations in the glomerular layer of the rat main olfactory bulb. Neurosci Res 23:73-88.

Kosaka K, Toida K, Aika Y, Kosaka T (1998) How simple is the organization of the olfactory glomerulus?: the heterogeneity of so-called periglomerular cells. Neurosci Res 30:101-110.

Kuo CT, Mirzadeh Z, Soriano-Navarro M, Rasin M, Wang D, Shen J, Sestan N, Garcia-Verdugo J, Alvarez-Buylla A, Jan LY, Jan YN (2006) Postnatal deletion of Numb/Numblike reveals repair and remodeling capacity in the subventricular neurogenic niche. Cell 127:1253-1264.

Lagace DC, Whitman MC, Noonan MA, Ables JL, DeCarolis NA, Arguello AA, Donovan MH, Fischer SJ, Farnbauch LA, Beech RD, DiLeone RJ, Greer CA, Mandyam CD, Eisch AJ (2007) Dynamic contribution of nestin-expressing stem cells to adult neurogenesis. J Neurosci, in press.

Leung CT, Coulombe PA, Reed RR (2007) Contribution of olfactory neural stem cells to tissue maintenance and regeneration. Nat Neurosci 10:720-726.

Lie DC, Colamarino SA, Song HJ, Desire L, Mira H, Consiglio A, Lein ES, Jessberger S, Lansford H, Dearie AR, Gage FH (2005) Wnt signalling regulates adult hippocampal neurogenesis. Nature 437:1370-1375.

Liu S, Wang J, Zhu D, Fu Y, Lukowiak K, Lu YM (2003) Generation of functional inhibitory neurons in the adult rat hippocampus. J Neurosci 23:732-736.

Lois C, Alvarez-Buylla A (1994) Long-distance neuronal migration in the adult mammalian brain. Science 264:1145-1148.

Long JE, Garel S, Alvarez-Dolado M, Yoshikawa K, Osumi N, Alvarez-Buylla A, Rubenstein JL (2007) Dlx-dependent and -independent regulation of olfactory bulb interneuron differentiation. J Neurosci 27:3230-3243.

Luskin MB (1993) Restricted proliferation and migration of postnatally generated neurons derived from the forebrain subventricular zone. Neuron 11:173-189.

Nakada Y, Hunsaker TL, Henke RM, Johnson JE (2004) Distinct domains within Mash1 and Math1 are required for function in neuronal differentiation versus cell-type specification. Development 131:1319-1330.

Ozen I, Galichet C, Watts C, Parras C, Guillemot F, Raineteau O (2007) Proliferating neuronal progenitors in the postnatal hippocampus transiently express the proneural gene Ngn2. Eur J Neurosci 25:2591-2603.

Parras CM, Schuurmans C, Scardigli R, Kim J, Anderson DJ, Guillemot F (2002) Divergent functions of the proneural genes Mash1 and Ngn2 in the specification of neuronal subtype identity. Genes and Development 16:324-338.

Parras CM, Galli R, Britz O, Soares S, Galichet C, Battiste J, Johnson JE, Nakafuku M, Vescovi A, Guillemot F (2004) Mash1 specifies neurons and oligodendrocytes in the postnatal brain. EMBO J 23:4495-4505.

Parras CM, Hunt C, Sugimori M, Nakafuku M, Rowitch D, Guillemot F (2007) The proneural gene Mash1 specifies an early population of telencephalic oligodendrocytes. J Neurosci 27:4233-4242.

Perez SE, Rebelo S, Anderson DJ (1999) Early specification of sensory neuron fate revealed by expression and function of neurogenins in the chick embryo. Development 126:1715-1728.

Pleasure SJ, Collins AE, Lowenstein DH (2000) Unique expression patterns of cell fate molecules delineate sequential stages of dentate gyrus development. J Neurosci 20:6095-6105.

Polito A, Reynolds R (2005) NG2-expressing cells as oligodendrocyte progenitors in the normal and demyelinated adult central nervous system. J Anat 207:707-716.

Reynolds R, Dawson M, Papadopoulos D, Polito A, Di Bello IC, Pham-Dinh D, Levine J (2002) The response of NG2-expressing oligodendrocyte progenitors to demyelination in MOG-EAE and MS. J Neurocytol 31:523-536.

Ridet JL, Malhotra SK, Privat A, Gage FH (1997) Reactive astrocytes: cellular and molecular cues to biological function. Trends Neurosci 20:570-577.

Rousseau A, Nutt CL, Betensky RA, Iafrate AJ, Han M, Ligon KL, Rowitch DH, Louis DN (2006) Expression of oligodendroglial and astrocytic lineage markers in diffuse gliomas: use of YKL-40, ApoE, ASCL1, and NKX2-2. J Neuropathol Exp Neurol 65:1149-1156.

Saghatelyan A, de Chevigny A, Schachner M, Lledo PM (2004) Tenascin-R 
mediates activity-dependent recruitment of neuroblasts in the adult mouse forebrain. Nat Neurosci 7:347-356.

Seki T, Namba T, Mochizuki H, Onodera M (2007) Clustering, migration, and neurite formation of neural precursor cells in the adult rat hippocampus. J Comp Neurol 502:275-290.

Seri B, Garcia-Verdugo JM, McEwen BS, Alvarez-Buylla A (2001) Astrocytes give rise to new neurons in the adult mammalian hippocampus. J Neurosci 21:7153-7160.

Seri B, Garcia-Verdugo JM, Collado-Morente L, McEwen BS, Alvarez-Buylla A (2004) Cell types, lineage, and architecture of the germinal zone in the adult dentate gyrus. J Comp Neurol 478:359-378.

Seri B, Herrera DG, Gritti A, Ferron S, Collado L, Vescovi A, Garcia-Verdugo JM, Alvarez-Buylla A (2006) Composition and organization of the SCZ: a large germinal layer containing neural stem cells in the adult mammalian brain. Cereb Cortex 16 [Suppl 1]:i103-111.

Srinivas S, Watanabe T, Lin CS, William CM, Tanabe Y, Jessell TM, Costantini F (2001) Cre reporter strains produced by targeted insertion of EYFP and ECFP into the ROSA26 locus. BMC Dev Biol 1:4.

Steiner B, Klempin F, Wang L, Kott M, Kettenmann H, Kempermann G (2006) Type-2 cells as link between glial and neuronal lineage in adult hippocampal neurogenesis. Glia 54:805-814.
Stump G, Durrer A, Klein AL, LutolfS, Suter U, Taylor V (2002) Notch1 and its ligands Delta-like and Jagged are expressed and active in distinct cell populations in the postnatal mouse brain. Mech Dev 114:153-159.

Sugimori M, Nagao M, Bertrand N, Parras CM, Guillemot F, Nakafuku M (2007) Combinatorial actions of patterning and HLH transcription factors in the spatiotemporal control of neurogenesis and gliogenesis in the developing spinal cord. Development 134:1617-1629.

van Praag H, Schinder AF, Christie BR, Toni N, Palmer TD, Gage FH (2002) Functional neurogenesis in the adult hippocampus. Nature 415:1030-1034.

Wang S, Sdrulla A, Johnson JE, Yokota Y, Barres BA (2001) A role for the helix-loop-helix protein Id2 in the control of oligodendrocyte development. Neuron 29:603-614.

Woodruff RH, Tekki-Kessaris N, Stiles CD, Rowitch DH, Richardson WD (2001) Oligodendrocyte development in the spinal cord and telencephalon: common themes and new perspectives. Int J Dev Neurosci 19:379-385.

Woodruff RH, Fruttiger M, Richardson WD, Franklin RJ (2004) Plateletderived growth factor regulates oligodendrocyte progenitor numbers in adult CNS and their response following CNS demyelination. Mol Cell Neurosci 25:252-262. 